\title{
Awareness and Usage of Emergency Contraceptives (EC) Among University Students: The Case of Ghana
}

\author{
Ellen OseiTutu ${ }^{1 *}$, Abigail A Aryeh-Adjei ${ }^{1}$ and Ernest Ampadu ${ }^{2}$ \\ ${ }^{1}$ Department of Adult Education and Human Resource Studies, University of Ghana, Ghana \\ ${ }^{2}$ Department of Teacher Education, University of Ghana, Ghana
}

Submission: May 30, 2018; Published: July 09, 2018

${ }^{*}$ Corresponding author: Ellen Osei Tutu, Department of Adult Education and Human Resource Studies, University of Ghana, Ghana,

Email: emosei-tutu@ug.edu.gh

\begin{abstract}
The purpose of this study was to examine the awareness and usage of Emergency Contraceptives (ECs) among university students. The data were collected using a structured questionnaire involving 1,871 students of the University of Ghana. The results showed that majority (87.9\%) ofthese students were aware of some regular contraceptives and ECs. The results also revealed that despite the awareness of these contraceptives among students, majority (70.4\%) had never used any form of contraceptives. The authors recommend that the university should use social media as a means of creating awareness of contraceptives in general and ECs in particular to the students.
\end{abstract}

Keywords: Emergency contraceptives; University students; Awareness; Unintended pregnancy; Usage

\section{Introduction}

Globally, it is estimated that each year, approximately twothirds (62\%) of all pregnancies are intended, and the rest (38\%) are unintended (Bongaarts \& Johansson, 2002 cited in Thapa [1]. Unintended pregnancies may pose dire consequences for women and their families, including possible unsafe abortion, increased maternal morbidity and mortality among others $[2,3]$.

In Jamaica for instance, unplanned pregnancies are common because Jamaican women are often exposed to unprotected or unwanted sex [4]. In addition, $40 \%$ of Jamaican women experience a pregnancy before they reach the age of 20 . Of these pregnancies, over $80 \%$ are unplanned [5].

The Centers for Disease Control and Prevention in 1997estimated that $86.1 \%$ of college students in the U.S.A. had engaged in sexual intercourse and that more than one-third of college women have had sexual intercourse with six or more partners [6].Unwanted pregnancies can influence the progress and future careers of students[7]. Unintended pregnancies may adversely affect students' studies and contribute highly to interrupted and truncated education, especially among female students in Ghana. The question is what happens to these unintended pregnancies? Some of these pregnancies end up in induced abortions.According to Ghana Statistical Service (GSS), Ghana Health Service \& Macro International [8], 15\% of women have ever had an induced abortion. Also, one in five women who had an abortion reported that, the main reason for the abortion was that, there was no money to take care of a baby. Furthermore, about one in ten women who had an abortion took more than one action to end their most recent pregnancies because the first action was not effective in terminating the pregnancy. This implies that these women were determined to get rid of their unwanted pregnancies and could have resorted to using ECs probably if they were available to them.

According to the latest Demographic and Health Survey (DHS) data in Ghana, 14\% of women between the ages of 1519 years were pregnant for the first time [9]. Most of them may not have been ready for it and were likely not have completed school. Unplanned pregnancies have been found to be high among women below age 20 and unmarried women. Research has shown that there is a direct relationship between level of education, socio-economic status and the likelihood to have unplanned pregnancies. For example, a research by OmaneAdjepong, [10], shows that the higher the education of a woman the less likely it is for her to have unplanned pregnancies and women who live in towns and non-income earners experience higher cases of unplanned pregnancies. Married women and females, in general, suffer many complications that come with unwanted pregnancies from rape, coerced unprotected sex 
and unsafe abortion. A large proportion of maternal deaths worldwide is as a result of unsafe induced abortions with Africa having a higher percentage (30-50) than Asia (20-25) as highlighted by Popov [11]. More than $60 \%$ of these pregnancies are among adolescents and are unintended; which result from contraception non-use, contraception method failure and rape $[12,13]$.

Students in higher institutions stand a higher risk of unintended pregnanciesas well as STIs, (including HIV/AIDS) as they are usually actively involved in probing and discovering, including sexual experimentation; hence often engaging in unintended and unsafe sex [14]. Against this backdrop, students have resorted to the use of contraceptives as a preemptive measure to curb any possibility of pregnancy. The usage of contraceptives has received much attention in most countries including Ghana. However, over the years the use of contraceptives in Sub-Saharan Africa has been far lower as compared to those of Latin America, the Caribbean and Europe [15]. Contraceptives are used for various reasons and different purposes; and statistics show that approximately one third of women in Ghana, either want to postpone the birth of their next child or do not want to have any more children but are not using any contraceptive to achieve this [9]. This is an issue of concern not for the women alone but for their partners as well. Regardless of the efficacy of various regular contraceptive methods, they are not $100 \%$ effective. There are situations like failure of barrier methods such as slippage, breakage or misuse of condom, failed coitus interruptus, and repeatedly unused oral contraceptive pills hence, the use of ECs [16].

According to the [17],emergency contraception refers to the method that can be used to prevent pregnancy in the first few days after sexual intercourse. It is also known as emergency birth control; emergency post-coital contraception; and post coital contraception and this has been in existence for over 40 years [18]. There are two main types of EC; the Yuzpe regimen and the copper bearing Inter Uterine Device (IUD). The EC pills regimen recommended by $\mathrm{WHO}$ is to be taken within five days (120 hours) of unprotected intercourse. The EC pills are more popular than the use of IUD. The IUD must be inserted within five days after unprotected sex. For the purpose of emergency contraception, it must be removed afterthe next menstrual cycle when it is certain that the woman is not pregnant [19].

It is argued that the use of ECs gives women the last chance to prevent unintended pregnancy [20]. There is growing interest in the potential impact that EC could have on unwanted pregnancies and unsafe abortions in Sub-Saharan Africa. Ninetynine percent of maternal mortality worldwide occurs in this part of the world, and nearly 20 million unsafe abortions occur each year [21]. Since the introduction of ECs in the 1970s, most of the studies conducted on them have been in developed countries, especially in the United States of America. Through the years, several changes have been made in the dosage, and there have also been several brands of EC pills in pharmacy shops in these countries. Advocacy has been going on such that ECs have moved from prescription-only to over the counter medicine which suggests that efforts are being made to make them accessible to all who need them.

In Ghana although ECs were introduced in 2000 [18], it was only in 2014 that the media started advertising them [22]. Moreover, the publication was sponsored by a project and so had a life span. Currently, there are few advertisements on ECs. Many of the studies in the developed world have mainly focused on the medical aspects of ECs. These are the composition of the pills, how it should be administered and how it works to prevent pregnancy. Very little attention in research is given to aspects such as the awareness and usage of ECs among students.

Also, missing in the literature especially within the Ghanaian context is research that examines the factors that influence the use of EC. In addition, most of these studies have ignored the views and perception of males about EC awareness and usage. In Ghana, few studies have been done on ECs including those of Baiden, [23] and [24].Virtually all studies conducted in Ghana have focused on only women probably because women are the ones who get pregnant and also use ECs. This study used both males and females as respondents, and they were asked the same questions on knowledge and usage. The females were asked to indicate whether they had ever used any ECs while the males were asked if their partners had ever used EC. This study provides the baseline information on ECs among university students in Ghana upon which further studies can be conducted to provide a holistic picture of the situation under consideration. This study, therefore, seeks to identify students' depth of knowledge of ECs and the extent to which they use ECs.Furthermore, this study explores the relationship between the characteristics of students and theirknowledge and usage of ECs.

\section{The Need and knowledge of EC}

The need for EC is well discussed in literature[25].One such instance was in India where girls had unprotected sex and used indigenous concoctions as post coital contraception [26]. The need for EC is also borne by the fact that some women have reported to clinics requesting for some and these women seem to know the stipulated time for use of EC as they reported within 72 hours of unprotected sex [27]. It has also been observed that women who are most likely to need and use EC are those using barrier methods [28].

Reports on knowledge of EC vary between developed and developing countries. Knowledge of the correct use of EC varies from $83 \%$ in developed countries to less than $60 \%$ in developing countries [29]. Inspite of efforts made to make EC known and available to those who need them, it seems a lot more needs to be done to achieve this. Unwanted pregnancies in London, for instance, have been as high as 40 percent because these women did not know about EC even though combined pill had been specially packaged and marketed as post coital contraceptive [30]. Similarly, 30\% of women seeking abortion in Central Oxford 
hospital did not know about emergency contraception and 11\% said that although they had heard about the method, they did not know how to obtain it [31].

However, knowledge of emergency contraception seems to be high in other parts of the world. In a study in Hong Kong, for instance, as many as $67 \%$ of women had heard of emergency contraception. It must be noted however that this knowledge may not have any depth as three percent of these women knew very little about it. Thirty-three percent claimed that they knew the correct time for using emergency contraception but fewer answered correctly [32].Knowledge has also been found to be high among students. In a study by Baiden, Awini and Clerk [23], among University of Ghana students, about $43.2 \%$ of the respondents had heard of modern EC methods.A higher percentage $(56.5 \%)$ of students in South Africa had heard about emergency contraception although fewer knew about the specific methods and the correct time limit for its use [33].

\section{Characteristics of People Who Know About EC}

It has been observed that although women claim to know about EC, their knowledge lacks depth and this could be attributed to their backgrounds. Among women who have heard of EC are those who have ever used contraceptives and have higher educational qualifications [28]. Among students for instance, those with medical and health related backgrounds are more likely than those without these backgrounds to know about ECs. Furthermore, they are more likely to also know about its costs. This is particularly so among pharmacy students whose knowledge of EC tends to increase as they progress in their studies [34]. Other studies with similar observations include those of Shelat et al. and [32].

Other characteristics that have been found to be associated with knowledge of EC are place of residence, age of respondents, marital status and nulliparous women. In the case of place of residence, those who reside in urban areas are more likely to know about EC than their counterparts who reside in rural areas [35]. The reason for this difference could be attributed to access; in that, all things being equal, residents of urban areas have more access to many things including contraceptives than rural areas. In relation to age, generally, teenagers and those younger than 30 years tend to be more aware of EC than older people [36]. Among these young ones, it is the sexually active who are more likely to know about EC [37].Also, nulliparous and unmarried women are more aware of EC compared to women who have children and those who are married respectively [32]. These two groups of women may share some similarities in that the unmarried women may not have children just like the nulliparous women and both groups aim at preventing unwanted pregnancies and therefore might be more eager to find ways of achieving this.

\section{Access, Knowledge and Use of EC}

It has been asserted earlier [35] that place of residence, specifically urban areas have more access to EC and thus more knowledge. However, access, although may lead to awareness, may not mean specific knowledge about appropriate use. One such study that has revealed this is that of Harper \& Ellertson[38] among Princeton University students in the U.S.A. These students had convenient access to EC through their student health service yet students remarked that they seldom discussed EC.

Contrary to some views that access to EC would lead to its abuse, some studies such as the one conducted by Planned Parenthood of Western Washington (PPWW) indicated that women who had received EC at a clinic had the tendency to go back and receiveregular contraceptive methods cited in Weldon, Hutchings, McAllister [39]. However, access to EC has not always had a positive effect as expresssed by Gross, Lafortune \& Low [40]. According to them, access to EC in the U.S.A. did not have any significant effect on birth or abortion rate. What it did was to change where the drug was obtained from, that is, from hospitals to pharmacies.

Use of EC has been found to be low among students in Slovenia and has been associated with certain factors Pinter, Verdenik, Grebenc \&Ceh [41]. Among the factors negatively associated with its usage were having a higher income, religious objection and the perception that EC is an abortifacient. On the other hand, women in Southern Nigeria use EC as their method of choice. This is because they have sex only occasionally and felt that EC was suitable for them. The additional reason for their choice was the stigma attached to the use of regular methods [42].

Some studies have examined both knowledge,and use of EC and identified a gap between knowledge and use of EC, for example Jackson et al. [36] in the U.S.A., Sorensen, Pedersen \& Nyrnberg [43]in Denmark and Aneblom, Larsson, Odlind \& Tyden [44]in Sweden. In all these studies, a greater proportion of the respondents knew of EC than the proportion that used it. Furthermore, a smaller proportion knew of the recommended time frame for its use. Awareness is generally higher than knowledge and usage of EC. Such observations have been made in places such as Korea by Kang \& Moneyham [45]and Nigeria by Zeleke, Zebenay \& Weldegerina [46]; Obiechina et al. cited in Kagashie et al., Kolawole, Abubakar \& Zaggi and Arowojolu \& Adekunle. Similar observations have been made in Tanzaniaby Kagashe et al.and in South Africa by Roberts et al.Most of these studies especially those from Nigeria were among students who happen to be the focus of this paper.

The implication of these studies is that the respondents used in these studies could be fairly young. They are also the ones who are likely to experience unplanned pregnancies because they have the tendency to be sexually active. The question then is if they are sexually active, are aware of EC, have some knowledge about its usage, why are they not using any? The reasons attributed to this were general lack of in depth knowledge and misconceptions about their usage. In a study on the differences between knowledge and use of EC across continents, Palermo, 
Bleck \& Westley [47]observed that in Africa knowledge of EC by all women ranges from $1.6 \%$ in Chad to $40.1 \%$ in Kenya while ever used among sexually experienced women ranged from less than $0.1 \%$ in Chad to $3.5 \%$ in Ghana. In Asia, the percentages for knowledge ranged from $3.3 \%$ in Timor-Leste to $28.7 \%$ in The Maldives and that of usage from $0.1 \%$ in Cambodia, Nepal and Timor-Leste to $0.6 \%$ for Maldives. In Europe and West Asia, while ever heard ranged from $4.6 \%$ in Azerbaijan to $48.5 \%$ in Ukraine ever use ranged from $0.6 \%$ in Turkey to $5.8 \%$ in Ukraine.In Latin America and the Caribbean, knowledge was quite high ranging from $13.2 \%$ in Haiti to $66.2 \%$ in Columbia with usage ranging from $0.4 \%$ in Haiti to $12.2 \%$ in Columbia. These observations confirm similar studies done earlier on the gap between knowledge and use.However, the additional observation is that there are some consistencies between knowledge and use in that countries with low knowledge also have low usage while those with high knowledge had high usage.

\section{Conceptual Framework}

The framework is made up of six unique but interrelated components: student's characteristics, awareness and depth of knowledge on EC, usage of EC, non-usage of EC, reasons for usage and reasons for non-usage. This framework looks at students' awareness of EC and what they know about EC. Those who have knowledge on EC may be using it or not. Likewise, there may be several reasons why student use EC or not. This is the focus of the paper as illustrated in the conceptual framework(Figure 1).

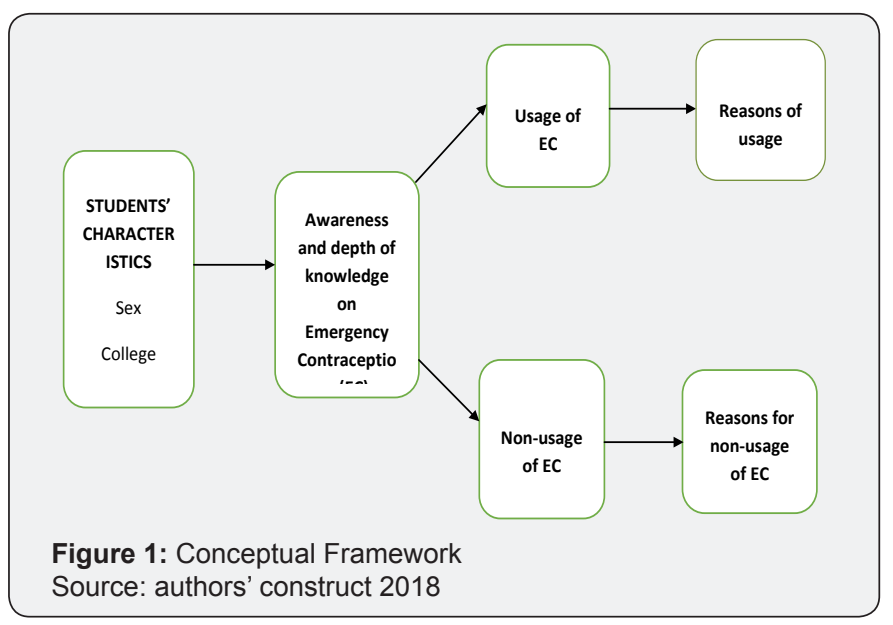

Methodology

\section{Research design}

As stated by Merriam [48], "being able to trust research results is especially important to professionals in applied fields, such as education, in which practitioners intervene in peoples' lives" (p. 198). To ensure high validity and reliability of the study so that people will trust the results, this study employs a robust research design aimed at helping the researchers to collect and analyse data to help provide a holistic picture of the situation under consideration. This study is situated within a positivist research paradigm where emphasis is based on observation and reason as means of understanding human behavior. This is because the researcher needs to concentrate on facts and must consider the world to be external and objective. This means the researcher should maintain minimal interaction with research participants when carrying out research. Another reason for using the positivist research paradigmis that samples have to be large for such a study so that the findings could be generalised to the larger population. An exploratory survey approach was used in collecting the data to achieve the objectives of this study. The survey approach was considered appropriate for the study as little is known when it comes to University students' awareness of ECs especially within the Ghanaian context. In addition to this, the survey approach was considered appropriate as the researchers were interested in establishing students' awareness and knowledge of ECs and its usage, by collecting data from a larger sample to understand the issue under consideration.

\section{Sample and Sampling Procedure}

In all, a total of 1,871 students from all the four colleges (that is College of Education, Basic and Applied sciences, Health Sciences and Humanities) of the University of Ghana were used. All the colleges of the University were used because all students belong to one college or the other. Students from second, third and fourth years completed the self-administered questionnaires. The first year students were not included because they had not been admitted into the University at the time the researchers were collecting the data. Colleague lecturers having different courses from these colleges permitted the research team to use about twenty minutes of their lecture time for students to fill the questionnaire.

\section{Ethical considerations}

Ethical clearance was received from University of Ghana's Research Ethics Committee (Ethics Committee for the Humanities). Also, students who completed the questionnaires were made to sign a consent form to indicate their willingness to participate in the study. Other ethical issues that were adhered to were anonymity and confidentiality.

\section{Research instrument}

The instrument used for the study was a self-administered questionnaire. The questionnaire had five different sections. Section A was used for eliciting information from the respondents regarding their biographic data. Section B was for gathering information about the respondents' reproductive history. Section Celicited information about the respondents' knowledge of ECs. Section D was used for collecting data about the respondents' attitudes toward EC. Section E, the last section, was used for collecting data about the respondents' usage of regular and ECs.

\section{Data collection and analysis procedures}

A total of 2,000 questionnaires were administered in the first semester of the 2016/2017 academic year of which 1,871 were fully completed, representing $93.5 \%$. All the copies of 
the questionnaires were examined to check for accuracy and completeness, but $6.5 \%$ did not qualify for this standard and were dropped.The questionnaires were numbered serially, edited, coded and fed into the computer where SPSS 21 software was used for the analysis. The analyses considered were that of descriptive and inferential statistics.

\section{Results}

\section{Students' knowledge of the existence of ECs}

To explorestudents' knowledge of the existence of ECs, the participants were asked to indicate whether they knew of any EC. The results show that an overwhelming majority of the respondents 1,645(87.9\%) indicated that they knew some ECs such as postinor 2 and plan B (pills). It was interesting to note that the sources of information about ECs varied; $907(48.5 \%)$ indicated that they got to know of ECs from the media and $682(36.5 \%)$ indicated that they got the information from friends and relatives. The rest of the respondents $282(15 \%)$ indicated that they got the information from a health worker. Students were asked where to obtain ECs from. The results were $57.9 \%$, indicating that they knew where ECs could be obtained, and $54.3 \%$ of the $57.9 \%$ indicating that they could get ECs from pharmacists(Table 1).

Table 1: Sex of respondents and knowledge of ECs.

\begin{tabular}{|c|c|c|c|c|c|c|}
\hline \multirow{2}{*}{$\begin{array}{c}\text { Knowledge } \\
\text { of ECs }\end{array}$} & $\begin{array}{c}\text { Sex of } \\
\text { Respondents }\end{array}$ & N & Mean & SD & F & P \\
\cline { 2 - 7 } & Male & 941 & 2.38 & 2.67 & & \\
\cline { 2 - 7 } & Female & 919 & 1.99 & 2.34 & 26.3 & 0.002 \\
\hline
\end{tabular}

An inferential statistical analysis shows that there is a significant difference between sex and knowledge of EC. A T-test analysis produced a $\mathrm{P}$ value of 0.002 indicating that females have more knowledge about ECs as compared to their male counterparts. However, it was interesting to note that there was no statistical difference between the college of the participants and their knowledge about ECs. While it was anticipated that at the colleges of Basic and Applied Sciences and Health Sciences the students will be more knowledgeable about EC as compared to their colleagues from the colleges of Education and Humanities, the results establish no significant difference.

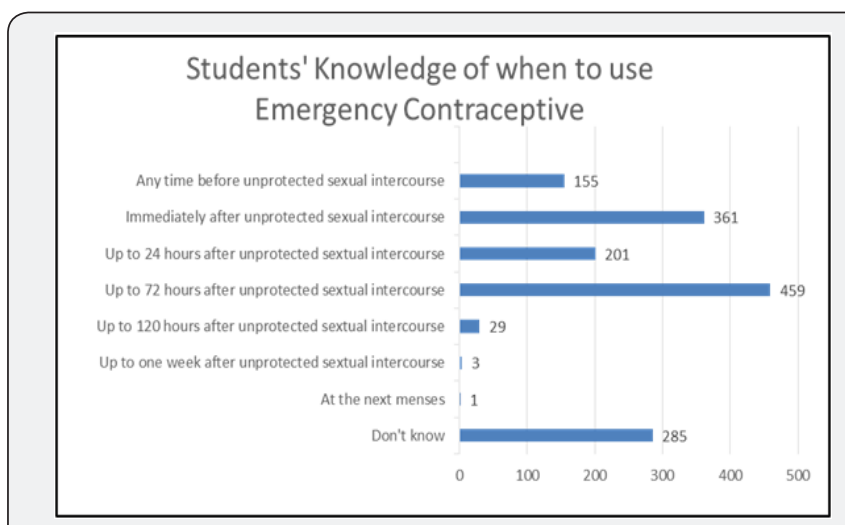

Figure 2: Students' Knowledge of when to use ECs
From Figure 2, students have some knowledge about when to use EC. It is evident from the figure that of the 1,494(79.8\%) students who had knowledge of ECs, majority (78.7\%) of them knew when it was appropriate to use it. They indicated that it should be used within 72 hours after having unprotected sex. From Figure 2, it can be argued that majority of the respondents have shown that they have knowledge of when to use ECs. Knowledge of ECs is very critical in the quest for avoiding unwanted pregnancies among students which could have a negative impact on their academic work.

On students' views about when to use ECs, a t-test analysis shows that there is a significant difference $(p=0.004)$ between females and males... More females than males stated that EC should be used up to 72 hours of unprotected sex.

\section{Extent to which students use ECs}

After examining students' knowledge on ECs, it was important to examine the extent to which they use ECs. To achieve this, the respondents were asked to indicate whether they had ever used ECs. It was, however, interesting to note that despite 1,256 (67.1\%) indicating they had knowledge on ECs, only $237(12.7 \%)$ had ever used EC. This confirms the findings of Kagashe et al. (2013) who have argued that there is a wide gap between knowledge of ECs and its usage. One of the factors accounting for this is the fact that majority of these students are abstaining as established in Figure 3.The study went further to find out whether there is a relationship between sex of respondents and usage of EC. From Table 2, there is a statistical difference between the usage of ECs and sex of respondents. A t-test analysis shows that females have used ECs more than their colleague male students (that is, the sexual partners of these male students).

Table 2: Sex of respondents and EC usage.

\begin{tabular}{|c|c|c|c|c|c|c|}
\hline \multirow{2}{*}{$\begin{array}{c}\text { Usage } \\
\text { of EC }\end{array}$} & $\begin{array}{c}\text { Sex of } \\
\text { Respondents }\end{array}$ & N & Mean & SD & F & P-Value \\
\cline { 2 - 7 } & Male & 941 & 3.87 & 3.02 & & \\
\cline { 2 - 7 } & Female & 919 & 3.37 & 2.79 & 43.4 & 0.01 \\
\hline
\end{tabular}

\section{Reasons for non-usage of ECs}

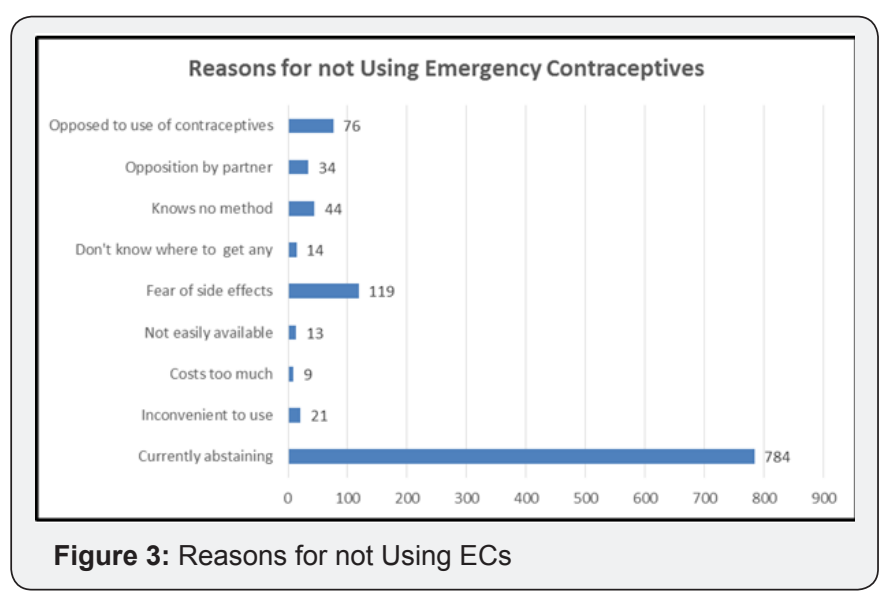


On the issue of non-usage of ECs, students were asked to indicate their agreement to some statements. In all, a total of $1,114(59.5 \%)$ students responded, and results are depicted in Figure 3.Even though students acknowledged they knew about ECs as well as where to find them, Figure 3 indicates that majority $(81.1 \%)$ of them were not using any because of two main reasons: $784(70.4 \%)$ were abstaining and 119 (10.7\%) because of the side effects. The results suggest that in as much as the respondents have knowledge and appreciate the importance of ECs, majority were of the view that they would prefer not to use ECs because they were abstaining or feared their side effects.

\section{Relationship Between College of Respondents and Knowledge and Usage of Ecs}

To understand the relationship between the College of respondents, and their knowledge and usage of ECs, a crosstabulation analysis was done, and the results are depicted in Figure 4.From Figure 4, 37.7\% of students who took part in the study where from College of Humanities, $28.7 \%$ from Basic and Applied Sciences, $21.4 \%$ from the College of Education and $17.2 \%$ from the College of HealthSciences.. The results showed that a very high percentage $(91.5 \%)$ of students from the College of Health Science knew about ECs as compared to their counterparts from the other colleges (for example, only $53.4 \%$ of students from the College of Education had knowledge about EC).

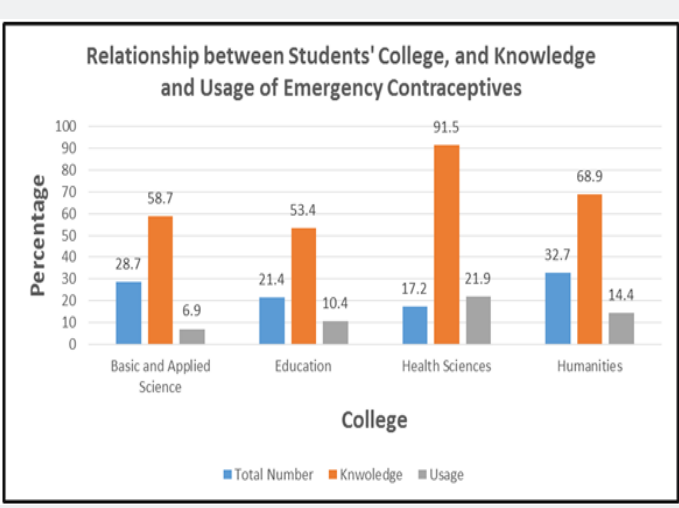

Figure 4: Relationship between Students' College, and Knowledge and Usage of ECs

In addition to this, the percentage of students who had used any form of EC was higher (21.9\%) in the College of Health Sciences followed by the College of Humanities (14.4\%), College of Education (10.4\%) and College of Basic and Applied Sciences (6.9\%). These differences could be attributed to the fact that students from the College of Health Sciences were more aware of contraceptives as it forms part of their programme of study. They may, therefore, know the advantages of ECs and also know how to use them effectively.

\section{Discussion and Implications}

Societies and for that matter students' awareness of ECs has become an issue of immense concern in schools and higher education institutions. As pointed out, students including the ones in higher institutions stand a higher risk of unintended pregnancies as a result of not having knowledge about ECs and hence its usage. Students' awareness of contraceptives in general and ECs in particularis therefore an important area to research into considering the needs of these students. It is evident from the results that majority (79.8\%) of the students who took part in the study had knowledge on ECs. This is a good sign for the Careers and Counselling Centre of the University of Ghana to enhance the reproductive health programmes of students and also to encourage the University Health Care Service to include these issues in the orientation programmes for fresh students. As suggested by Omane-Adjepong et al. [10] unwanted pregnancies havebecome an issue of concern to many students, and there is the need for university authorities to provide students with the needed information on regular and ECs.

Most students were aware of ECs but had never used any. That is, majority $(87.9 \%)$ of the respondents indicated that they had heard or had knowledge of some form of ECs, but $70.4 \%$ indicated that they had never used any because they are abstaining. The results conform to the findings from Kolawole et al. [49]. Also, similar to the findings of Shelat [50], the results from this study revealed that students from the Colleges of Basic and Applied Sciences and Health Sciences knew more about EC than their colleges from other colleges.However, while Roberts et al. [33] established that, there is an inverse relationship between knowledge of EC and when to use it, the results from this study showed otherwise[51,52].

\section{Conclusion}

Students' knowledge about ECs is a great asset to the students as individuals, the university and to the nation. This knowledge will go a long way to help students to become conversant with the importance of ECs and the challenges associated with them. However, even though most of the students knew about ECs, very few of them use or have ever used any. This therefore calls for further research to understand how these students protect themselves from unwanted pregnancies, and the effect of the methods they use.

In addition to this, the results have shown that students get information about ECs mainly from the media. Considering the calibre of students and their desire for social media platforms, it is necessary to make very good use of these platforms as a means of getting them informed about the issue under consideration. Therefore, the university authorities and those in charge of reproductive health issues in the university must be proactive and use social media as one of the means of communicating and creating awareness on issues concerning students, especially those on reproductive health. Although majority of these students have reported that they are abstaining, it is important that they become aware of the importance and how to use ECs so that when the need arises they can make good use of them. These students are considered as the future of this country and 
agents of change; hence the knowledge that they acquire will go a long way to help them know about the importance of EC and its usage. Overall, knowledge and use of emergency contraception by tertiary students is limited. There is a need for carefully designed educational programmes on emergency contraception on various campuses.

\section{Acknowledgement}

This project was made possible with financial support from the University of Ghana Research Fund.

\section{References}

1. Thapa S, Marks JD, Corey E (2012) Unintended pregnancy: toward understanding the issues and addressing research gaps. Prepared for online course in Sexual and Reproductive Health, Geneva Foundation for Medical Research and Training, Geneva, Switzerland.

2. Singh S, Sedgh G, Hussain R (2010) Unintended pregnancy: Worldwide levels, trends, and outcomes. Stud Fam Plann 41(4): 241-250.

3. Santelli J, Richet R, Hatfield-Timajchy K, Gilbert BC, Curtis K, et al. (2003) The measurement and meaning of unintended pregnancy. Perspect Sex Reprod Health 35(2): 94-101.

4. Friedman JS, McFarlane CP, Morris L (1997) Reproductive Health Survey, Jamaica 1997, Young Adult Report, Department of Health, and Human Services, Centers for Disease Control and Prevention, Atlanta, Georgia.

5. Eggleston E, Jackson J, Hardee K (1999) Sexual attitudes and behaviour among adolescents in Jamaica. International Family Planning Perspectives 25(2): 78-84.

6. Synovitz L, Herbert E, Carlson G, Kelly RM (2005) College Students Sexuality Education, Sexual Behavioural Intent. American Journal of Health Studies 20(1-2): 47-57.

7. Kagashe GAB, Maregesi SM, Mashaka A (2013) Availability, awareness, attitude and knowledge of ECs in Dar Es Salaam. Journal of Pharmaceutical Science and Research 5(11): 216-219.

8. Ghana Statistical Service (GSS), Ghana Health Service (GHS), and Macro International (2009) Ghana Maternal Health Survey 2007. Calverton, GSS and Macro International, Maryland, USA.

9. Ghana Statistical Service (2015) Ghana Demographic and Health Survey 2014. GSS, GHS and ICF International, Rockville, Maryland, USA.

10. Omane-Adjepong M, Oduro FT, Annin K (2012) Multinomial regression analysis of unplanned pregnancies in Ahafo Ano South district, Ghana. American International Journal of Contemporary Research 2(12): 9097.

11. Popov AA (1991) Family planning and induced abortion in the USSR: basic health and demographic characteristics. Stud Fam Plann 22(6): 368-377.

12. Altankhuyagin G, Falkigham J, Brown J (2007) Determinants of current contraceptive use and method choice in Mongolia. Journal of Biosocial Science 39(6): 801-817.

13. Gliem JA, Gliem RR (2003) Calculating, interpreting, and Reporting Cronbach's Alpha Reliability Coefficient for Likert, Type Scales Midwest Research to Practice Conference in Adult, Continuing, and Community Education, pp. 82-88.

14. Abler RM, Sedlacek WE (1989) Freshman sexual attitudes and behaviours over a 15-year period. Journal of College Student Development 30(3): 201-209.

15. Westoff CF (2012) Unmet Need for Modern Contraceptive Methods. DHS Analytical Studies No. 28. Office of Population Research Princeton University, USA.
16. International Consortium for Emergency Contraception (2003) Emergency Contraceptive Pills: Medical and Service Delivery Guidelines. In: ( $2^{\text {nd }}$ edn), Washington DC, USA.

17. World Health Organization (2012) Emergency contraception. Factsheet No 244.

18. Tilahun FD, Assefa T, Belachew T (2010) Predictors of Emergency Contraceptive use among regular female students at Adama University, Central Ethiopia. Pan Afr Med J 7: 16-33.

19. Planned Parenthood Federation of America (2013) Emergency contraception history and access.

20. Trussell J, Raymond EG, Cleland K (2018) Emergency contraception: A last chance to prevent unintended pregnancy. Princeton University Princeton, USA.

21. AbouZahr C, Wardlaw T (2001) Maternal mortality at the end of a decade: signs of progress? Bull World Health Org 79(6): 561-568.

22. Ghana News (2014) Ghana's market witnesses new contraceptives.

23. Baiden FA, Clerk C (2002) Perception of university students in Ghana about emergency contraception. Contraception 66(1): 23-26.

24. Appiah-Agyekum NN, Kayi EA (2013) Students' perceptions of contraceptives in University of Ghana. J Family Reprod Health 7(1): $39-44$.

25. Dupont S, Webber J, Dass K, Thornton S (2002) Emergency Contraceptive Pill (ECP) and sexual risk behaviour. Int J STD AIDS 13(7): 482-485.

26. Nayyar A (2000) Increasing access to emergency contraception in India. Health and Population-Perspectives and Issues 23(3): 123-133.

27. Shawe J, Ineichen B, Lawrenson R (2001) Emergency contraception: Who are the users? J Fam Plann Reprod Health Care 27(4): 209-212.

28. George J, Turner J, Cooke E, Hennessy E, Savage W, et al. (1994) Women's knowledge of emergency contraception. Br J Gen Pract 44(387): 451-454.

29. Larsson M, Aneblom G, Eurenius K, Westerling R, Tydén T, et al. (2006) The Adoption of a New Contraceptives methods - surveys and intervention regarding emergency contraception. Acta Obstetricia et Gynecologica Scandinavica 85(9): 1142-1143.

30. Burton R, Savage W, Reader F (1990) Morning after Pill is the wrong Name for it: Women's knowledge of Postcoital Contraception in Tower Hamlets. British Journal of Family Planning 15: 119-121.

31. Duncan G, Harper C, Ashwell E, Mant D, Buchan H, et al. (1990) Termination of Pregnancy: Lessons for Prevention. British Journal of Family Planning 15: 112-117.

32. Lee SWH, Wai MFY, Lai LYH, Ho PC (1999) Women's knowledge of and attitudes towards emergency contraception in Hong Kong: questionnaire survey. Hong Kong Med J 5(4): 349-352.

33. Roberts C, Moodley J, Esterhuizen T (2004) Emergency contraception: knowledge and practices of tertiary students in Durban, South Africa. J Obstet Gynaecol 24(4): 441-445.

34. Hope DL, Hattingh HL, King MA (2016) Australian pharmacy students' knowledge, attitudes, and behaviors regarding emergency contraception. Pharmacy Education 16(1): 11-17.

35. Tajure N (2010) Knowledge, attitude and practice of emergency contraception among graduating female students of Jimma University, Southwest Ethiopia. Ethiop J Health Sci 20(2): 91-97.

36. Jackson R, Schwarz E, Freedman BL, Darney P (2000) Knowledge and willingness to use emergency contraception among low-income postpartum women. Contraception 61(6): 351-357.

37. Ottesen S, Narring F, Renteria SC, Michaud PA (2002) Emergency contraception among teenagers in Switzerland: a cross-sectional 
survey on the sexuality of 16- to 20-year-olds. J Adolesc Health 31(1): 101-110.

38. Harper CC, Ellertson EC (1995) Knowledge and Perceptions of Emergency Contraceptive Pills among a College-Age Population: A qualitative Approach. Family Planning Perspectives 27: 149-154.

39. Weldon M, Hutchings J, McAllister S, Harris C, Larsen-Mills D, et al. (2006) Expanding access to emergency contraception through state systems: The Washington State experience. Perspectives on Sexual and Reproductive Health 38(4): 220-224.

40. Gross T, Lafortune J, Low C (2013) What Happens the Morning After? The Costs and Benefits of Expanding Access to Emergency Contraception. J Policy Anal Manage 33(1): 70-93.

41. Pinter B, Verdenik I, Grebenc M, Ceh F (2009) Sexual activity and contraceptive use among Secondary School Students in Slovenia. European Journal of Contraception and Reproductive Health Care 14(2): 127-133.

42. Renne EP (1998) Postinor use among young women in southern Nigeria: a research note. Reproductive Health Matters 6(11): 107-114.

43. Sorensen MB, Pedersen BL, Nyrnberg LE (2000) Differences between users and non-users of emergency contraception after a recognized unprotected intercourse. Contraception 62(1): 1-3.

44. Aneblom G, Larsson M, Odlind V, Tyden T (2002) Knowledge, use and attitudes towards EC pills among Swedish women presenting for induced abortion. BJOG 109(2): 155-160.
45. Kang HS, Moneyham L (2008) Use of Emergency Contraceptive pills and Condoms by College Students: a Survey. Int J Nurs Stud 45(5): 775783.

46. Zeleke G, Zebanay Z, Weldegerina B (2009) Knowledge, attitude, and practice of ECs in Bahir Dar University female students. Nigerian Journal of Representative Health 3: 59-64.

47. Palermo T, Bleck J, Westley E (2014) Knowledge and Use of Emergency Contraception: A Multicountry Analysis. Int Perspect Sex Reprod Health 40(2): 79-86.

48. Merriam SB (1998) Qualitative Research and Case study Applications in Education. In: ( $2^{\text {nd }}$ edn) Jossey-Bass Publishers, San Francisco, USA, pp. 275.

49. Kolawole TOCA, Abubakar M, Zaggi H (2015) Emergency Contraceptives Use among Female Students at Ahmadu Bello University, Zaria Kaduna State. Online Journal of New Horizon in Education 5(3): 41-48.

50. Shelat PR, Hihoriya NH, Kumbar S (2012) Knowledge and attitude towards the use of emergency contraceptive pills among college students. Int J Basic Clin Pharmacol 1(2): 77-84.

51. Emergency Contraception in Africa (2013) Sexuality, contraception, unplanned pregnancies and abortion in West Africa and Morocco: The ECAF Survey. Population 68(1): 7-14.

52. Arowojolu AO, Adekunle AO (2000) Perception and practice of emergency contraception by post-secondary school students in southwest Nigeria. Afr J Reprod Health 4(1): 56-65.

\section{Your next submission with Juniper Publishers will reach you the below assets}

- Quality Editorial service

- Swift Peer Review

- Reprints availability

- E-prints Service

- Manuscript Podcast for convenient understanding

- Global attainment for your research

- Manuscript accessibility in different formats

( Pdf, E-pub, Full Text, Audio)

- Unceasing customer service

Track the below URL for one-step submission https://juniperpublishers.com/online-submission.php 